\title{
Strain characteristics of non-ferrous metals obtained on the basic of different loads
}

\author{
Andrzej Kurek, Justyna Koziarska, and Tadeusz Łagoda* \\ Opole University of Technology, Faculty of Mechanical Engineering, Ul. Mikołajczyka 5, 45-271 Opole, Poland
}

\begin{abstract}
The paper presents the comparison of the results of experimental fatigue tests for the 6082-T6 and 2017-T4 aluminium alloys. Tests performed under two types of load conditions. That is tensilecompressive and oscillatory bending. The results are obtained by applying the Basquin's stress-life equation and strain-life equations: Kandil's equation, Langer's equation and the authors' own equation. On the basis of own experimental studies and the relevant physical relations, the stress and strain amplitudes occurring in bent rods under smooth specimens, were calculated according to the elastoplastic model. The results were then used to compare both types of loads with different types of control..
\end{abstract}

\section{Introduction}

The subject of material fatigue is an important issue in our economy every day. The effects of tension and bending are known virtually in each branch of industry [1], therefore it is not a surprise that these two loading states are also considered with reference to material fatigue $[2,3]$. The majority of current fatigue characteristics are developed in tension-compression conditions. Unfortunately, this state of loading is very rare in real mechanical structures subject to fatigue loads [4]. Variable bending occurs more often [5]. As a result of this, the relation between fatigue characteristics for tension-compression and oscillatory bending constitutes an interesting and up-to-date subject for considerations [6]. It should be emphasised here that in the case of bending, these characteristics are most often developed using the model of a perfectly elastic body.

This paper compares the characteristics of tensioncompression and oscillatory bending for the model of a perfectly elastic and elasto-plastic body, using the models of strain characteristics [7-9]. The analysis has been performed on the basis of fatigue tests completed for the 6082-T6 and 2017(A)-T4 aluminium alloys in the two considered loading states. It has been proven that in the case of the elasto-plastic body model, fatigue characteristics for oscillatory bending do not lie under the fatigue characteristic for tension-compression. This shows that we are safe using conventional tensioncompression characteristic to calculate fatigue life of structures subject to oscillatory bending [10].

When analysing the issue of tension-compression we can't forget to mention the Manson-Coffin-Basquin model (MCB) [11-13]:

$$
\varepsilon_{a, t}=\varepsilon_{a, e}+\varepsilon_{a, p}=\frac{\sigma_{f}^{\prime}}{E}\left(2 N_{f}\right)^{b}+\varepsilon_{f}^{\prime}\left(2 N_{f}\right)^{c}
$$

where: $\varepsilon_{a, t}$ - total strain amplitude expressed as the sum of the amplitudes of elastic strain $\varepsilon_{a, e}$ and plastic strain $\varepsilon_{a, p}, 2 N_{f}$ - the number of loading reversals (semi-cycles), $E$ - the Young's modulus,

$\sigma_{f}^{\prime}, b$-coefficient and exponent of the fatigue strength, respectively, $\varepsilon_{f}^{\prime}, c$ - coefficient and exponent of the plastic strain, respectively.

The original MCB characteristic has been developed for tension-compression while analysing the strain, stress and the number of cycles until destruction.

Model (1) is used only in the case, when it is possible to determine separately both elastic $\varepsilon_{a e}$ and plastic $\varepsilon_{a p}$ component of total strain $\varepsilon_{a t}[14]$.

Then, for cyclic loading we obtain:

$$
\varepsilon_{a e}=\frac{\sigma_{a}}{E}
$$

and

$$
\varepsilon_{a p}=\varepsilon_{a t}-\varepsilon_{a e}
$$

This relation is defined by the Ramberg-Osgood equation [15]:

$$
\varepsilon_{a, t}=\varepsilon_{a, e}+\varepsilon_{a, p}=\frac{\sigma_{a}}{E}+\left(\frac{\sigma_{a}}{K^{\prime}}\right)^{\frac{1}{n^{\prime}}}
$$

where: $\sigma_{a}-$ stress amplitude, $K^{\prime}-$ cyclic strength coefficient, $n^{\prime}$ - cyclic strengthening exponent.

In 1910 Basquin [11] proposed the fatigue Table showing the relation between the number of cycles until destruction and stress amplitude in a double-logarithmic 
system $\log \left(\sigma_{a}\right)-\log \left(N_{f}\right)$, and the approximating formula, which can be expressed as below in the exponential form for tension-compression:

$$
\sigma_{a}=\sigma_{f}^{\prime}\left(2 N_{f}\right)^{b}
$$

or

$$
\log N_{f}=A+m \log \sigma_{a}
$$

where: $N_{f}$ - fatigue life in cycles, $\sigma_{\mathrm{a}}-$ stress amplitude for tension-compression or bending, $A, m$ - regression model constants.

Another issue has been shown in the study [16], where it is pointed out that the sense of plastic strain amplitude in the expression (1) depends on fatigue life, and thus $c$ is not a constant value.

Moreover, various authors proposed other empirical model making total strain amplitude dependent on the number of cycles. Among these models there is the Langer [17] proposal, which is used in numerous studies and promoted e.g. by Manson [18], [19] and Chrop [20].

$$
\log N_{f}=A-B \log \left(\varepsilon_{a c}-C\right),
$$

where: A, B, C - constants to select special form of the characteristic for a given material.

Another characteristic is proposed by Kandil [21] and Gorash [22], in the following form:

$$
\log \varepsilon_{a c}=A-B \log \left(N_{f}\right)+C \log ^{2}\left(N_{f}\right),
$$

where: A, B, C - constants to select special form of the characteristic for a given material.

Since in case of bending it is not possible to separate elastic and plastic component, then characteristic (1) cannot be used but it is possible to use characteristics (7) or (8), or other empirical form of a strain characteristic. For example, this may be a combination of characteristics (7) and (8) in the following form:

$$
\log \left(\varepsilon_{a c}-D\right)=A-B \log \left(N_{f}\right)+C \log ^{2}\left(N_{f}\right),
$$

where: A, B, C, D - constants to select special form of the characteristic for a given material.

An extensive review of fatigue characteristics can be found e.g. in the study [23]. The new form, which is proposed there, requires 4 material constants to be determined, same as for the popular characteristic MCB (1).

In the literature there is no simple model allowing determination of elasto-plastic strains and stresses for smooth rods at bending. However, it has been confirmed empirically many times that normal strain distribution for bending is linear in cross-section:

$$
\varepsilon_{\mathrm{a}}(\mathrm{x})=\varepsilon_{\mathrm{a} \max } \frac{\mathrm{x}}{\mathrm{R}}
$$

where: $\mathrm{x}$ - the distance from bending plane, $\mathrm{R}-$ maximum height (radius in case of round component $/ \mathrm{rod} /$ ).

The basic relationship that has to be satisfied is that normal stresses, which appear both in an elastic and elasto-plastic model, must compensate the preset bending moment, that is:

$$
\mathrm{M}_{\mathrm{b}}=\int_{\mathrm{S}} \sigma(\mathrm{x}, \mathrm{y}) \mathrm{xdS}
$$

while, the relationship between stress and strain amplitude may be expressed using the Ramberg-Osgood equation (4). Fig. 1 shows an example distribution of stresses and strains at bending.
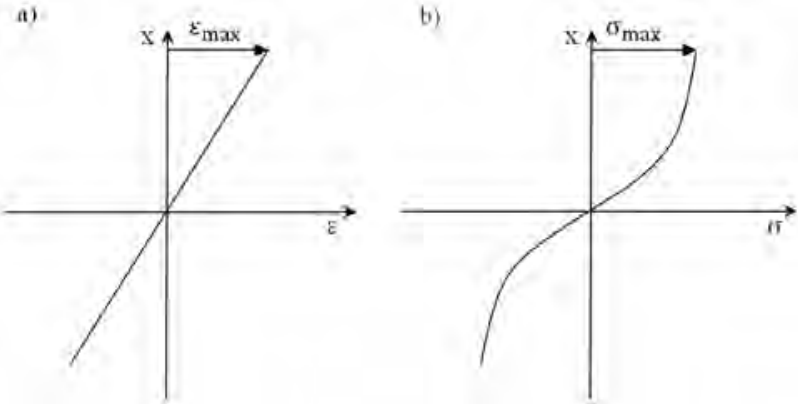

Fig.1. Distribution of strain (a) and stress (b) in a test piece subject to bending

Whereas, Fig. 2 shows values in the test piece cross-section, required to calculate distributions of stresses and bending moment according to the elastoplastic body model.

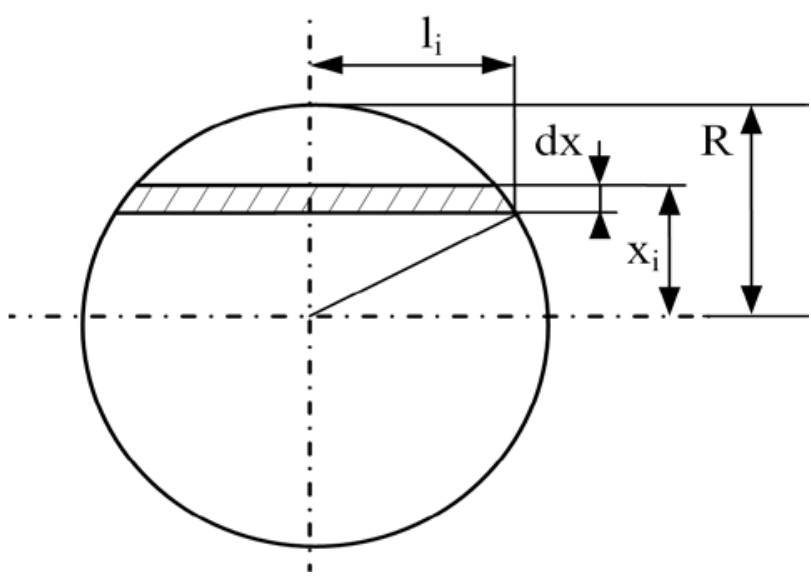

Fig. 2. Cross-section of test piece subject to bending

\section{Experimental studies}

The studies have been carried out for test pieces made of the 6082-T6 and 2017-T4 aluminium alloys.

Chemical constitution of the tested material is shown in Table 1. The basic mechanical properties of the discussed material are specified in Table 2 .

Table 1. Chemical constitution of the aluminium alloys (in \%) $-\mathrm{Al}$ - the rest

6082

\begin{tabular}{|c|c|c|c|c|c|c|c|}
\hline $\mathrm{Cu}$ & $\mathrm{Mg}$ & $\mathrm{Mn}$ & $\mathrm{Si}$ & $\mathrm{Fe}$ & $\mathrm{Zr}+\mathrm{Ti}$ & $\mathrm{Zn}$ & $\mathrm{Cr}$ \\
\hline$<0.1$ & $0.6 \div 1.2$ & $0.4 \div 1$ & $0.7 \div 1.3$ & $<0.5$ & $<0.1$ & $<0.2$ & $<0.25$ \\
\hline
\end{tabular}




2017A
\begin{tabular}{|c|c|c|c|c|c|c|c|}
\hline $\mathrm{Cu}$ & $\mathrm{Mg}$ & $\mathrm{Mn}$ & $\mathrm{Si}$ & $\mathrm{Fe}$ & $\mathrm{Zr}+\mathrm{Ti}$ & $\mathrm{Zn}$ & $\mathrm{Cr}$ \\
\hline $3.5 \div 4.5$ & $0.4 \div 1$ & $0.4 \div 1$ & 0.6 & $<0.7$ & $<0.25$ & $<0.25$ & $<0.25$ \\
\hline
\end{tabular}

Table 2. The basic mechanical parameters of aluminium alloys

\begin{tabular}{|c|c|c|c|c|c|}
\hline Aluminium & $\begin{array}{c}\mathrm{E}, \\
\mathrm{GPa}\end{array}$ & $\begin{array}{c}\mathrm{R}_{\mathrm{p} 0.2}, \\
\mathrm{MPa}\end{array}$ & $\mathrm{R}_{\mathrm{m}}, \mathrm{MPa}$ & $\mathrm{A}_{5} \%$ & $v$ \\
\hline 6082 & 77 & 365 & 385 & 27.2 & 0.32 \\
\hline $2017 \mathrm{~A}$ & 72 & 395 & 545 & 21 & 0.32 \\
\hline
\end{tabular}

\section{Test for tension-compression}

The low-cycle tests for tension-compression were performed in cooperation with the Institute Laboratory for Materials and Structures Testing at UTP - University of Science and Technology in Bydgoszcz [24] for 6082$\mathrm{T} 6$ and at Opole University of Technology [25] for 2017(A)-T4.

The purpose of tests was to find basic fatigue characteristics for test pieces made of aluminium alloy at ambient temperature.

16 test pieces were used in the tests for 6082-T6 and 10 test pieces for 2017(A)-T4. The tests were performed according to the standard PN-84/H-04334.

The results of fatigue tests at single-axis tension-compression are compared in Table 3. Material constants appearing in the Manson-Coffin-Basquin (1) and Ramberg-Osgood (4) characteristics have been determined on the basis of these results. These values are compared in Table 4.

Table 3. Cyclic parameters of aluminium alloys

\begin{tabular}{|c|c|c|c|c|c|c|}
\hline & $\begin{array}{c}\text { K', } \\
\text { MPa }\end{array}$ & n' & $\begin{array}{c}\sigma_{f}^{\prime}, \\
\text { MPa }\end{array}$ & $\varepsilon^{\prime}{ }_{f}$ & $b$ & $c$ \\
\hline $6082-T 6$ & 616 & 0.099 & 533 & 0.185 & -0.066 & -0.634 \\
\hline 2017A-T4 & 617 & 0.066 & 643 & 1.879 & -0.065 & -0.988 \\
\hline
\end{tabular}

The third tests type for 2017(A)-T4 [26] was tension-compression at a constant amplitude of energy parameter ( $W_{a}=$ const) for 19 test pieces [27], where:

$$
\mathrm{W}(\mathrm{t})=0.25\{|\sigma(\mathrm{t})| \varepsilon(\mathrm{t})+\sigma(\mathrm{t})|\varepsilon(\mathrm{t})|\},
$$

which in load amplitude-based form eventually gives

$$
\mathrm{W}_{\mathrm{a}}=0.5 \sigma_{\mathrm{a}} \varepsilon_{\mathrm{a}},
$$

where $\mathrm{W}_{\mathrm{a}}$ is amplitude of strain energy parameter.

\section{Test for oscillatory bending}

Fatigue tests for oscillatory bending were carried out using fatigue-testing machines belonging to the laboratory of the Department of Mechanics and Machine Design at Opole University of Technology.

The "diabolo" type cylindrical test pieces without geometrical notch were used in fatigue tests. The geometry of test pieces used results from simplified localisation of spot characterised by highest stresses, and shown in Fig. 3. The starting material was round rod made of the 6082 and 2017(A) aluminium alloys, $\phi 16 \mathrm{~mm}$ in diameter. The tests in cyclic conditions under controlled moment involved using 25 test pieces, and under controlled strain - 25 test pieces as well for 6082T6 and 21 test pieces for 2017(A)-T4).

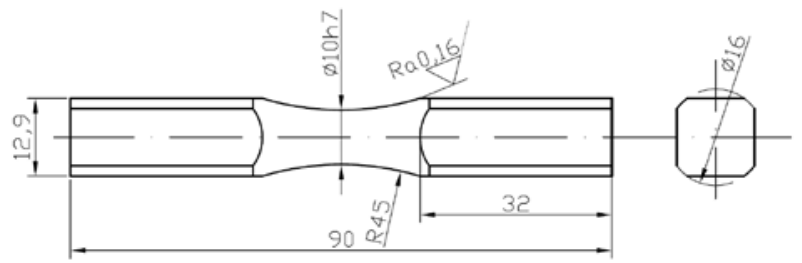

Fig. 3. The shape and dimensions of a test piece for fatigue tests

The cyclic (constant-amplitude) tests were carried out on the MZGS-100 test bench designed by Achtelik. Fig. 4 shows the view of a fatigue-testing machine. The MZGS-100 test bench consists of a propulsion system, head, loading system, and control and measurement setup. The trajectory of bending moment $\mathrm{M}$ loading the test piece was the parameter monitored during the tests.

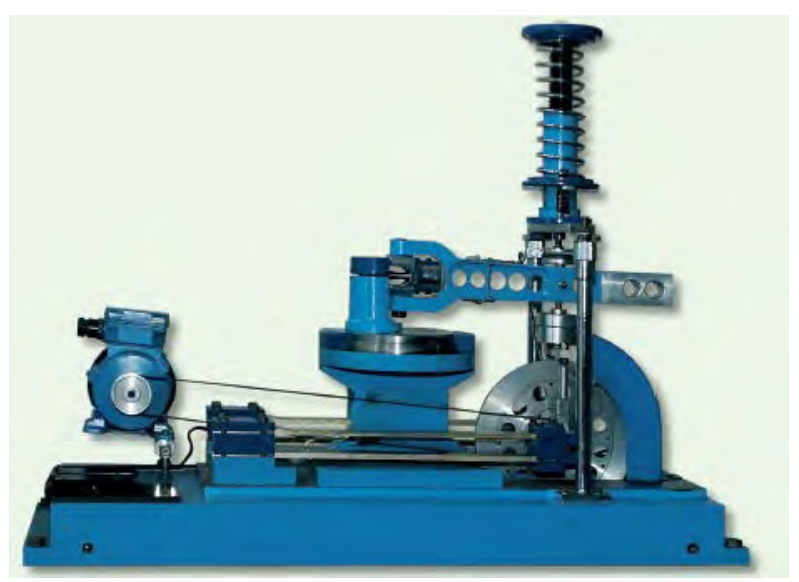

Fig. 4. The setup for fatigue tests under controlled moment

Fatigue tests under controlled strain were performed using a new setup shown in Fig. 5. In this case, lever excursion amplitude has been controlled, then ensuring control of test piece strain.

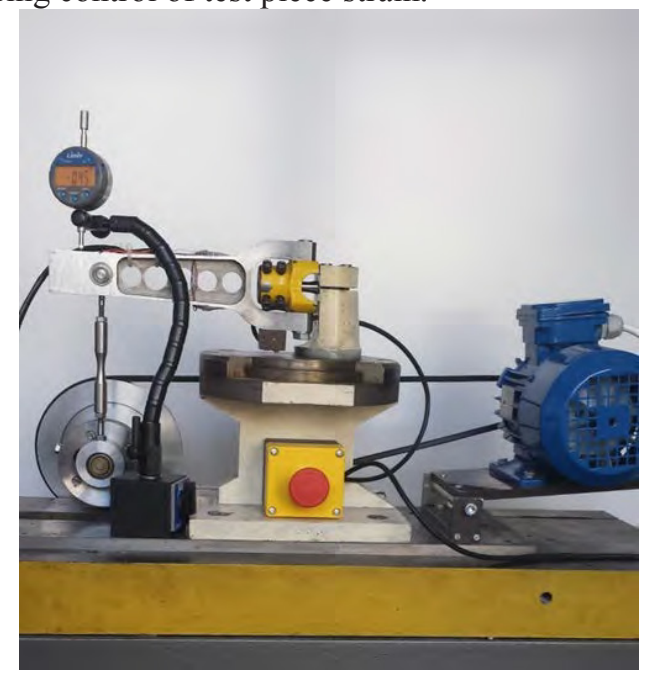

Fig.5. The setup for fatigue tests under controlled strain 
In case of fatigue tests carried out both under controlled moment and strain amplitude, the stiffness or moment amplitude drop by $15 \%$ respectively was taken as fatigue life, this corresponds with a moment when crack became visible with bare eyes (ca. $1 \mathrm{~mm}$ ).

Fig. 6 presents typical test pieces cross-section after oscillatory bending. In this photo we can clearly see the initiation point and neutral plane, in relation to which bending has been occurring. On the figure you can also see the long furrows which start on the surface of the material in the origin of the crack and they extend deeper into the material perpendicular to the bending surface.

a)

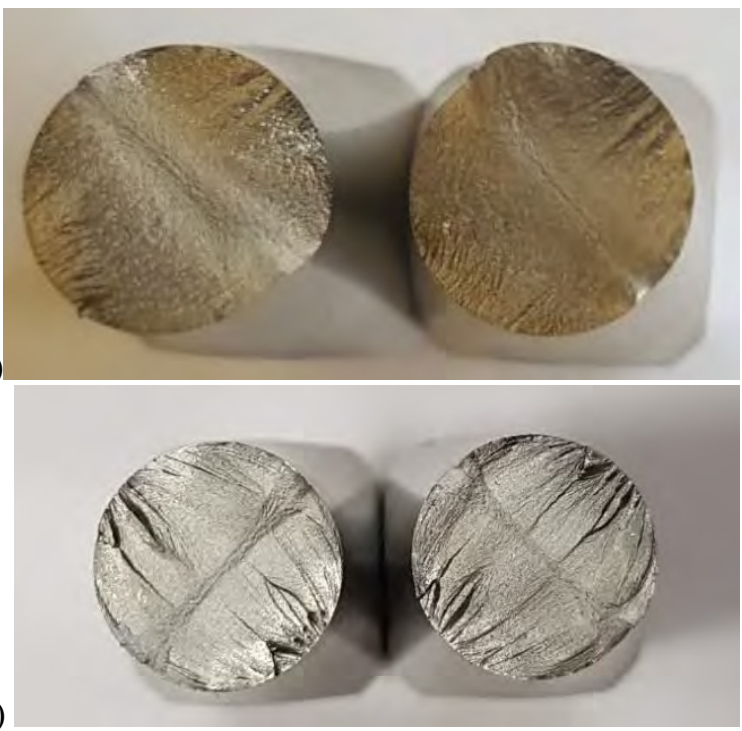

Fig.6. An example test piece photo taken after oscillatory bending test a) 6082-T6 b) 2017(A)-T4

\section{Comparison of test results}

Completed tests and respective calculations provided grounds for determining fatigue characteristics, cumulatively shown in the illustrations. Constants appearing in the formulae are compared in successive Tables.

Successive analyses concern strain characteristics. The Manson-Coffin-Basquin strain-life curve (1) has been the first one analysed. The Fig. 7 and Table $4-5$ allows observing that in practice all three characteristics overlap and it is possible to find one cumulative MCB curve. However, it should be noted that in the case of bending the MCB characteristic can be determined only owing to previously defined Ramberg-Osgood model (4), this allows separating elastic and plastic component of strain. Considering this, it seems necessary to seek other characteristics, in which there is no need to divide strain into an elastic and plastic component. Finding such a model will allow determining fatigue characteristics under controlled strain at bending on relatively simple and inexpensive machines.

The Langer characteristic (7) has been employed first. It is the simplest one, and originally it assumes linear character in a double-logarithmic system. Fig. 8 compares these characteristics for individual tests.
Parameters of these characteristics are confronted in Table 6 and 7. Completed data analysis indicates that the characteristic for tension-compression and the cumulative characteristic approximate the empirical data incorrectly. As a result of this, it cannot be used for correct description of the empirical data. The Kandil characteristic (8) has been taken as the second one. It is more complex than the Langer characteristic, and as it may be concluded from Fig. 9 and data collected in Table 8 and 9, it describes experimental test results by far better. This applies both to the description of these results for individual tests, and the cumulative characteristic determined for all tests. The last characteristic used is the one proposed by the Authors of this study in form of (9). Another, fourth parameter to be determined appears in this characteristic. Analysis of Fig. 10 and data contained in Table 10 and 11 proves that, same as in case of the Langer characteristic, this characteristic describes all test results very well, both individually and for all tests jointly. Analysis of correlation coefficients for all three analysed strain characteristics (Tables 4 - 11) indicates that the best match of combined characteristics is ensured in case of the model proposed by the Authors of this study.

Table 4. Comparison of parameters of the analysed characteristics according to the Manson-Coffin-Basquin model for 6082-T6

\begin{tabular}{|l|c|c|c|c|}
\hline & $\mathrm{b}$ & $\mathrm{c}$ & $\begin{array}{c}\sigma_{\mathrm{f}}^{\prime}, \\
\mathrm{MPa}\end{array}$ & $\varepsilon_{\mathrm{f}}^{\prime}$ \\
\hline $\begin{array}{l}\text { Bending } \\
\left(\mathrm{M}_{\mathrm{a}}=\text { const }\right)\end{array}$ & -0.101 & -0.657 & 733 & 0.188 \\
\hline $\begin{array}{l}\text { Bending } \\
\left(\varepsilon_{\mathrm{a}}=\text { const }\right)\end{array}$ & -0.113 & -0.636 & 823 & 0.275 \\
\hline $\begin{array}{l}\text { Tension- } \\
\text { compression } \\
\left(\varepsilon_{\mathrm{a}}=\text { const }\right)\end{array}$ & -0.066 & -0.634 & 533 & 0.185 \\
\hline All (combined) & -0.091 & -0.582 & 649 & 0.148 \\
\hline
\end{tabular}

Table 5. Comparison of parameters of the analysed characteristics according to the Manson-Coffin-Basquin model for $2017(\mathrm{~A})-\mathrm{T} 4$

\begin{tabular}{|l|c|c|c|c|}
\hline & $\mathrm{b}$ & $\mathrm{c}$ & $\begin{array}{c}\sigma_{\mathrm{f}}^{\prime}, \\
\mathrm{MPa}\end{array}$ & $\varepsilon_{\mathrm{f}}^{\prime}$ \\
\hline $\begin{array}{l}\text { Tension- } \\
\text { compression } \\
\left(\varepsilon_{\mathrm{a}}=\text { const }\right)\end{array}$ & -0.063 & -0.962 & 627 & 1.305 \\
\hline $\begin{array}{l}\text { Tension- } \\
\text { compression } \\
\left(\mathrm{W}_{\mathrm{a}}=\text { const) }\right.\end{array}$ & - & - & - & - \\
\hline Bending $\left(\mathrm{M}_{\mathrm{a}}=\right.$ const) & - & - & - & - \\
\hline All (combined) & - & - & - & - \\
\hline
\end{tabular}



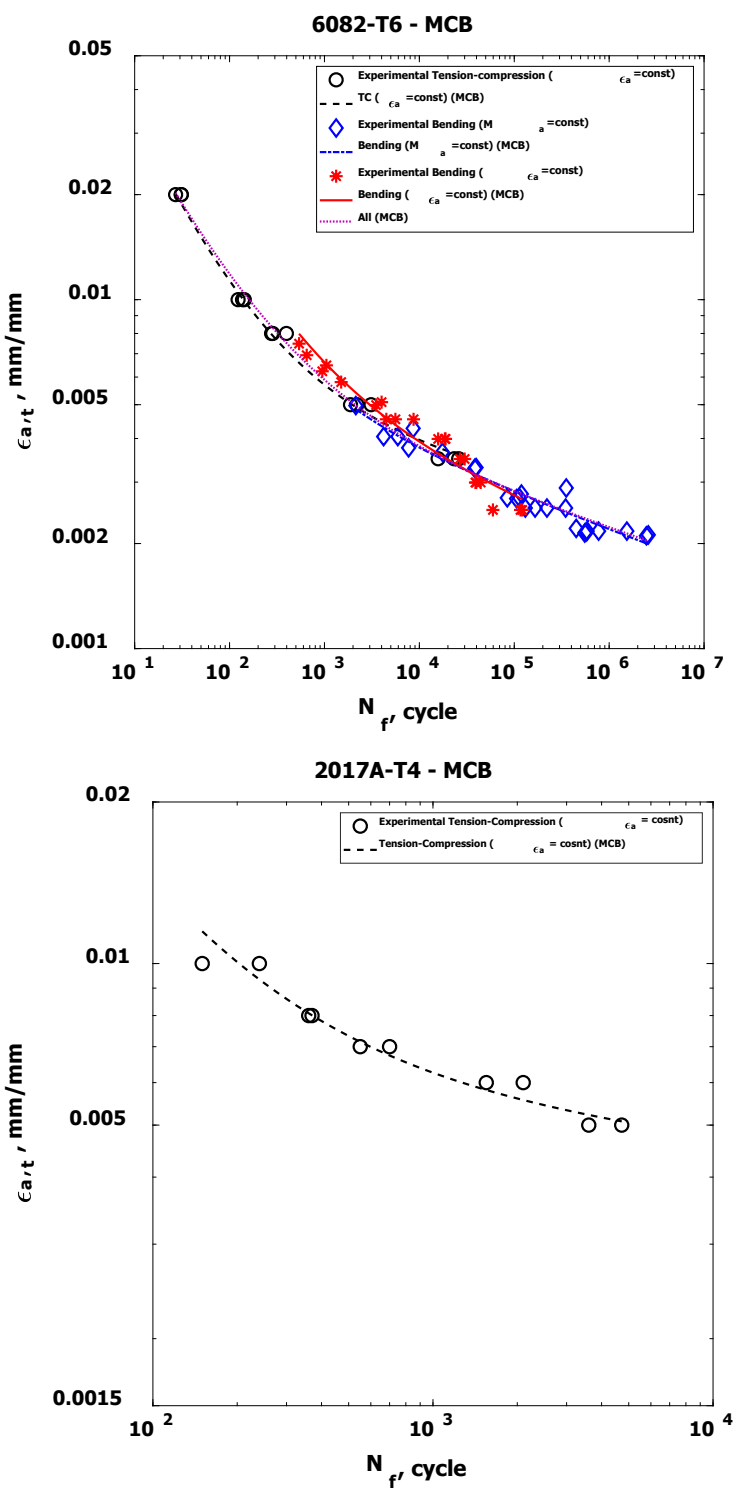

Fig. 7. Fatigue characteristics according to the Manson-CoffinBasquin model a) 6082-T6, b) 2017(A)-T4

Table 6. Comparison of parameters of the analysed characteristics according to the Langer model for 6082-T6

\begin{tabular}{|l|c|c|c|c|} 
& $\mathrm{A}$ & $\mathrm{B}$ & $\mathrm{C}$ & $\mathrm{R}^{2}$ \\
\hline Bending $\left(\mathrm{M}_{\mathrm{a}}=\right.$ const $)$ & -1.898 & 0.129 & 0.002 & 0.94 \\
\hline Bending $\left(\varepsilon_{\mathrm{a}}=\right.$ const $)$ & -1.611 & 0.193 & 1.068 & 0.98 \\
\hline $\begin{array}{l}\text { Tension-compression } \\
\left(\varepsilon_{\mathrm{a}}=\text { const }\right)\end{array}$ & -1.200 & 0.350 & 0.002 & 0.96 \\
\hline All (combined) & -1.284 & 0.295 & 0.200 & 0.93 \\
\hline
\end{tabular}

Table 7. Summary of the parameters of analysed fatigue life values according to Langer's model for 2017(A)-T4

\begin{tabular}{|l|c|c|l|c|}
\hline & $\mathrm{A}$ & $\mathrm{B}$ & $\mathrm{C}$ & $\mathrm{R}^{2}$ \\
\hline $\begin{array}{l}\text { Tension-compression } \\
\left(\varepsilon_{\mathrm{a}}=\text { const }\right)\end{array}$ & -1.523 & 0.218 & 1.247 & 0.95 \\
\hline $\begin{array}{l}\text { Tension-compression } \\
\left(\mathrm{W}_{\mathrm{a}}=\text { const }\right)\end{array}$ & -1.829 & 0.1407 & 0 & 0.95 \\
\hline Bending $\left(\mathrm{M}_{\mathrm{a}}=\right.$ const) & -1.949 & 0.1079 & 0 & 0.78 \\
\hline All (combined) & -1.746 & 0.1516 & 0.0016 & 0.91 \\
\hline
\end{tabular}
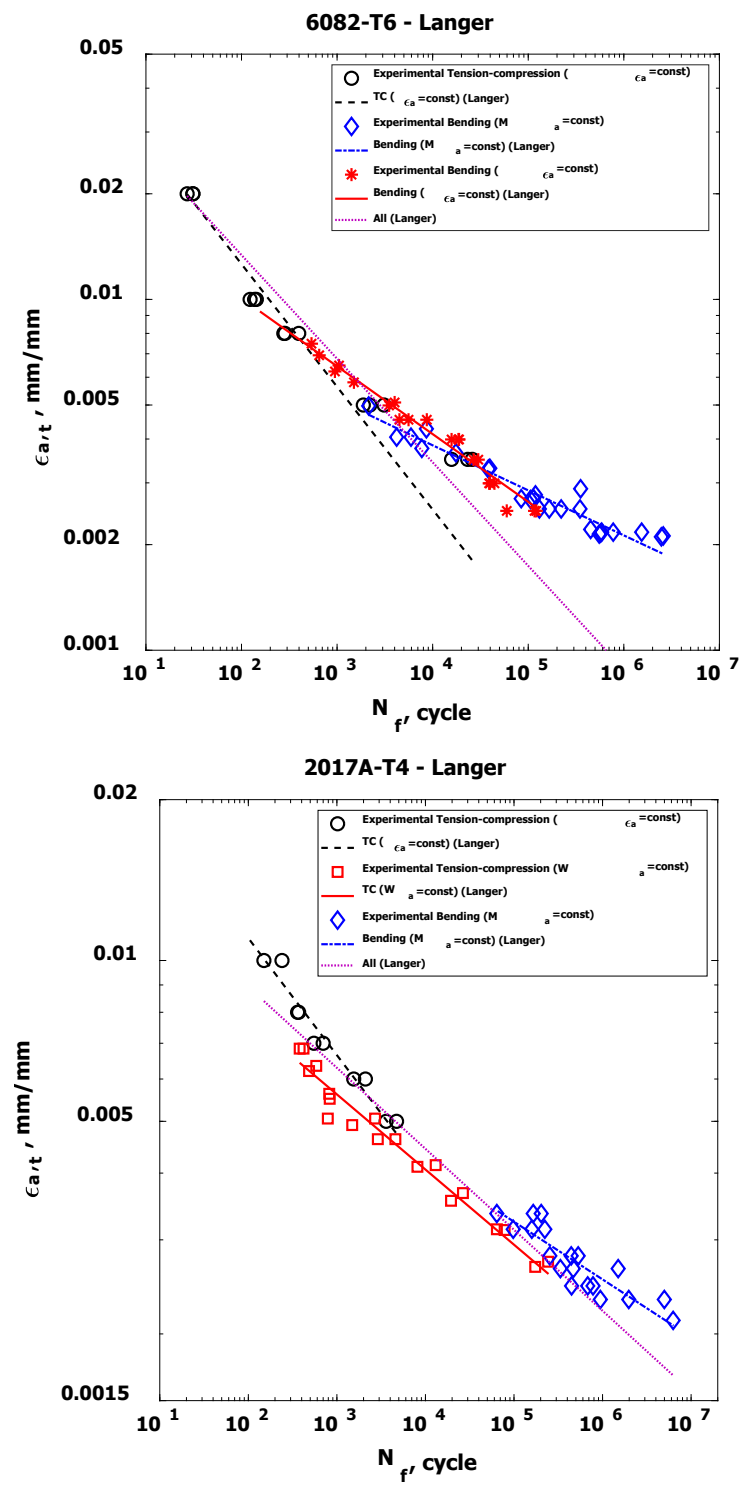

Fig.8. Fatigue characteristics according to the Langer model a) 6082-T6, b) 2017(A)-T4

Table 8. Comparison of parameters of the analysed characteristics according to the Kandil model for 6082-T6

\begin{tabular}{|l|c|c|c|c|}
\hline & $\mathrm{A}$ & $\mathrm{B}$ & $\mathrm{C}$ & $\mathrm{R}^{2}$ \\
\hline Bending $\left(\mathrm{M}_{\mathrm{a}}=\right.$ const $)$ & -1.571 & 0.274 & 0.0154 & 0.95 \\
\hline Bending $\left(\varepsilon_{\mathrm{a}}=\right.$ const $)$ & -1.72 & 0.132 & -0.0082 & 0.98 \\
\hline $\begin{array}{l}\text { Tension-compression } \\
\left(\varepsilon_{\mathrm{a}}=\text { const }\right)\end{array}$ & -0.835 & 0.703 & 0.7033 & 0.99 \\
\hline All (combined) & -1.035 & 0.524 & 0.0436 & 0.99 \\
\hline
\end{tabular}

Table 9. Summary of the parameters of analysed fatigue life curves according to Kandil's model for 2017(A)-T4 


\begin{tabular}{|l|c|c|c|c|}
\hline & $\mathrm{A}$ & $\mathrm{B}$ & $\mathrm{C}$ & $\mathrm{R}^{2}$ \\
\hline $\begin{array}{l}\text { Tension- } \\
\text { compression } \\
\left(\varepsilon_{\mathrm{a}}=\text { const }\right)\end{array}$ & -1.139 & 0.4945 & 0.04851 & 0.96 \\
\hline $\begin{array}{l}\text { Tension- } \\
\text { compression } \\
\left(\mathrm{W}_{\mathrm{a}}=\text { const }\right)\end{array}$ & -1.1611 & 0.2636 & 0.01642 & 0.96 \\
\hline $\begin{array}{l}\text { Bending } \\
\left(\mathrm{M}_{\mathrm{a}}=\text { const }\right)\end{array}$ & -1.283 & 0.3432 & 0.02059 & 0.79 \\
\hline All (combined) & -1.305 & 0.3944 & 0.03007 & 0.94 \\
\hline
\end{tabular}
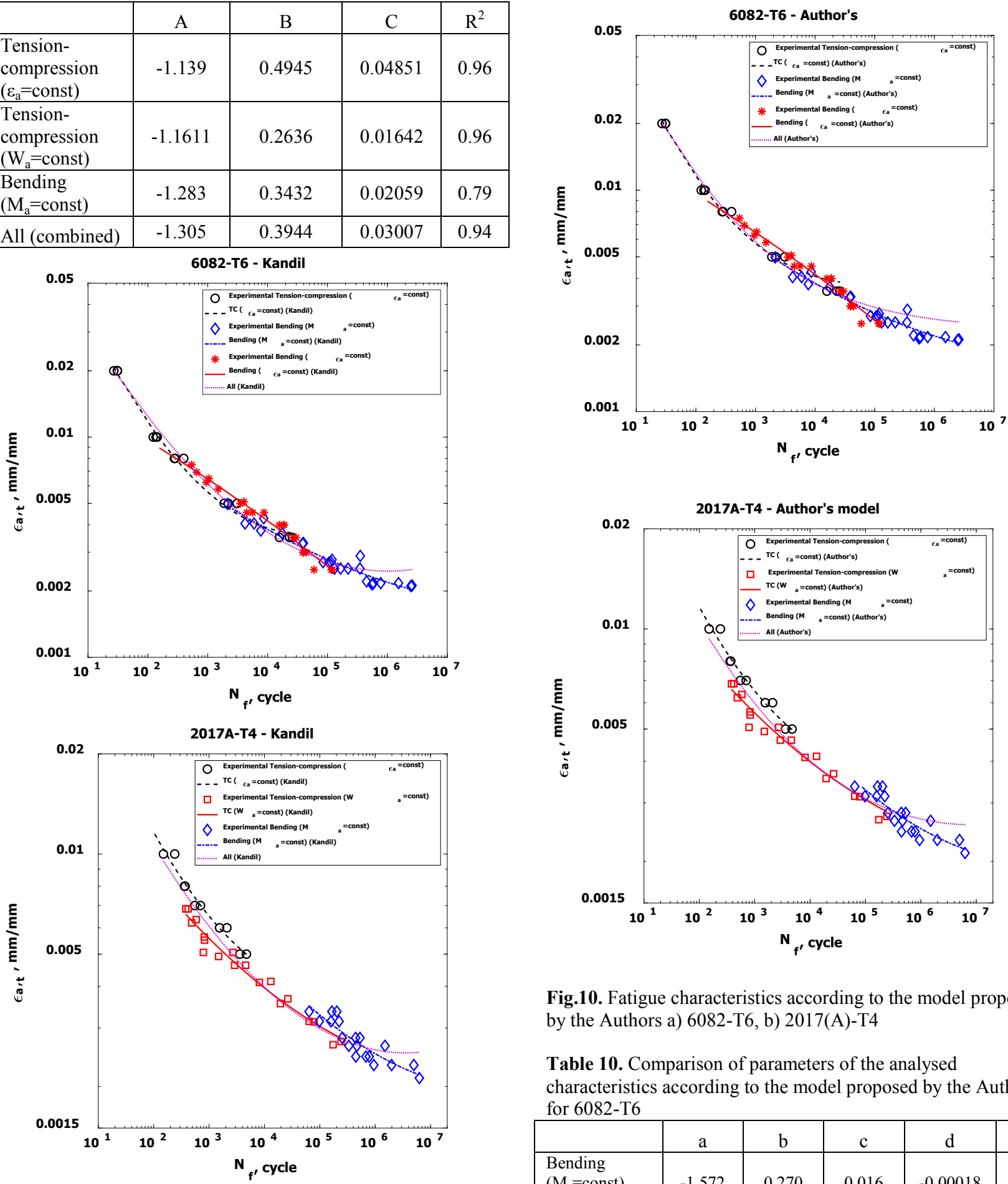

Fig.9. Fatigue characteristics according to the Kandil model a) 6082-T6, b) 2017(A)-T4

Fig.10. Fatigue characteristics according to the model proposed by the Authors a) 6082-T6, b) 2017(A)-T4

Table 10. Comparison of parameters of the analysed characteristics according to the model proposed by the Authors for 6082-T6

\begin{tabular}{|l|c|c|c|c|c|}
\hline & $\mathrm{a}$ & $\mathrm{b}$ & $\mathrm{c}$ & $\mathrm{d}$ & $\mathrm{R}^{2}$ \\
\hline $\begin{array}{l}\text { Bending } \\
\left(\mathrm{M}_{\mathrm{a}}=\text { const }\right)\end{array}$ & -1.572 & 0.270 & 0.016 & -0.00018 & 0.95 \\
\hline $\begin{array}{l}\text { Bending } \\
\left(\varepsilon_{\mathrm{a}}=\text { const }\right)\end{array}$ & -1.709 & 0.136 & -0.007 & -0.00023 & 0.98 \\
\hline $\begin{array}{l}\text { Tension- } \\
\text { compression } \\
\left(\varepsilon_{\mathrm{a}}=\text { const }\right)\end{array}$ & -0.788 & 0.761 & 0.079 & 0.00141 & 0.99 \\
\hline $\begin{array}{l}\text { All } \\
\text { (combined) }\end{array}$ & -0.965 & 0.595 & 0.038 & 0.00192 & 0.99 \\
\hline
\end{tabular}


Table 11. Summary of the parameters of analysed fatigue life values according to the authors' for 2017(A)-T4

\begin{tabular}{|l|c|c|c|c|c|}
\hline & $\mathrm{A}$ & $\mathrm{B}$ & $\mathrm{C}$ & $\mathrm{D}$ & $\mathrm{R}^{2}$ \\
\hline $\begin{array}{l}\text { Tension- } \\
\text { compression } \\
\left(\varepsilon_{\mathrm{a}}=\text { const }\right)\end{array}$ & -1.15 & 0.485 & 0.048 & -0.00022 & 0.96 \\
\hline $\begin{array}{l}\text { Tension- } \\
\text { compression } \\
\left(\mathrm{W}_{\mathrm{a}}=\text { const) }\right.\end{array}$ & -1.62 & 0.267 & 0.016 & 0.00036 & 0.96 \\
\hline $\begin{array}{l}\text { Bending } \\
\left(\mathrm{M}_{\mathrm{a}}=\text { const }\right)\end{array}$ & -1.28 & 0.343 & 0.021 & -0.00010 & 0.79 \\
\hline $\begin{array}{l}\text { All } \\
\text { (combined) }\end{array}$ & -1.29 & 0.425 & 0.031 & 0.00083 & 0.94 \\
\hline
\end{tabular}

\section{Conclusions}

1. Experimental tests carried out for test pieces made of the 6082-T6 and 2017(A)-T4 aluminium alloys under strain control in conditions of single-axis tension-compression, and both under strain control and moment control for oscillatory bending are much the same and independent on loading method.

2. The tests under controlled strain may be replaced by oscillatory bending carried out on a simple, modern test bench instead of the basic tensioncompression test performed using large fatiguetesting machines.

3. The best known Mason-Coffin-Basquin strain characteristic describes the results of all experimental tests very well; however, it can be used only when there is a possibility to divide strains into the elastic and plastic components. Analysing the results of specific tests, it becomes clear that fatigue life is almost identical across all tests; therefore, a common fatigue life can be determined for each of the analysed models.

4. The Langer strain characteristic describes fatigue test results incorrectly, and it is not recommended for use to characterise fatigue test results.

5. The best match of fatigue characteristic to all experimental data is ensured by the four-parameter characteristic proposed by the Authors, which is a fragment of a parabola in a double-logarithmic system, and it is slightly better than the threeparameter Kandil characteristic.

\section{References}

1. A. Kurek, J. Koziarska, T. Lagoda, Energetyka, 11, 673-675 (2016)

2. M. Kurek, T. Łagoda, D. Katzy, Material Testing, 56, 92-95 (2014)

3. A. Kulesa, A. Kurek, T. Lagoda, H. Achtelik, K. Kluger, Acta Mechanica et Automatica, 10, 62-65 (2016)

4. K. Walat, T. Łagoda, M. Kurek, Material Testing, 57, 160-164 (2015)

5. S. S. Manson, U. Muralidharan, Fatigue \& Fracture Engineering Materials \& Structures, 9, 357-372 (1987)
6. A. Kulesa, A. Kurek, T. Lagoda, H. Achtelik, K. Kluger, Solid State Phenomena, 250, 85-93 (2016)

7. V. Troschenko, Multiaxial and Fatigue Design, ESIS 21, (Edited by A. Pinueau, G. Cailletaud and T. C .Lindley), Mechanical Engineering Publications, London, 335-348 (1996)

8. M. M. Megahed, Fatigue \& Fracture of Engineering Materials \& Structures, 13, 361-374 (1990)

9. D. Krzyżak, M. Kurek, T. Łagoda, D. Sówka Materialwissenschaft und Werkstofftechnik, 45, 1018-1029 (2014)

10. A. Niesłony, A. Kurek, Applied Mechanics and Materials, Trans Tech Publications, 104, 197-205 (2012)

11. O.H. Basquin, Am. Soc. Test. Mater. Proc., 10, 625630 (1910)

12. L. F. Coffin, Trans ASME, 76, 931-950 (1954)

13. S. S. Manson, Experimental Mechanics, 5, 193-226 (1965)

14. V. M. Radhakrishnan, NASA Technical Memorandum 105840, NASA-TM-105840, E-7283, NAS 1.15:105840, 11 (1992)

15. W. Ramberg, W. R. Osgood, Technical Note No. 902, National Advisory Committee for Aeronautics, Washington DC (1943)

16. V. M. Radhakrishnan, NASA Technical Memorandum 105840, p.11, (1992)

17. B. F. Langer, ASME J. Basic Eng, 84, 389-402 (1962)

18. S. S. Manson, Fatigue of Engineering Materials and Structures, 1, 37-57 (1979)

19. S. S. Manson, Fatigue: Experimental Mechanics, 193-226 (1965)

20. O. K. Chopra, U.S. Nuclear Regulatory Commission (1999)

21. F. A. Kandil Standards Measurement \& Testing Project No. SMT4-CT97-2165, 1, 1-26 (2000)

22. Y. Gorash, H. Chen, Engineering Failure Analysis, 34, 308-323 (2013)

23. A. Niesłony, A. Kurek, Ch. El Dsoki, H. Kaufmann, International Journal of Fatigue, 39, 88-94 (2012)

24. St. Mroziński St. Raport $\mathrm{z}$ badań, UTP w Bydgoszczy, Bydgoszcz (2012)

25. W. Będkowski, T. Łagoda, J. Słowik, Materials Science, 43, 492-498 (2007)

26. W. Będkowski, J. Słowik, Raport Nr 1/WM/2004, Wydział Mechaniczny, Politechnika Opolska (2004)

27. T. Łagoda, Int. J. Fatigue, 23, 481-489 (2001) 
This work has been carried out under the grant of National Science Centre (Poland) no. 2015/19/B/ST8/01115 